\title{
An island mixing effect in the coastal Gulf of Maine*
}

\author{
D. W. Townsend ${ }^{1}$, C. M. Yentsch ${ }^{1}$, C. E. Parker ${ }^{1}$, \\ W. M. Balch ${ }^{2}$ \& E. D. True ${ }^{3}$ \\ ${ }^{1}$ Bigelow Laboratory for Ocean Sciences; McKown Point, West Boothbay Harbor, \\ Maine 04575, USA, \\ ${ }^{2}$ Institute of Marine Resources, A-018, Scripps Institution of Oceanography, University \\ of California San Diego; La Jolla, California 92093, USA, \\ ${ }^{3}$ Department of Mathematics, Norwich University; Northfield, Vermont 05663, USA
}

\begin{abstract}
The analyses of density fields, nitrate and chlorophyll $\alpha$ concentrations, Lagrangian current measurements and remote sensing of sea surface temperatures demonstrated an island mixing effect for Monhegan Island (Gulf of Maine). The island's unique location within the westward flowing arm of a counterclockwise basin gyre and the bathymetry surrounding the island result in a combination of vertical mixing and upwelling to produce chlorophyll maxima on the north and south flanks of the island.
\end{abstract}

\section{INTRODUCTION}

The influence of island systems on the biological productivity and/or standing stocks of the surrounding waters has been known for some time (Doty \& Oguri, 1956). In large scale systems it results primarily from the interactions of currents and island obstructions which often produce an upwelling of deeper nutrient-rich waters on the upstream side of the island, thus stimulating biological production. This island mass effect, as it was originally called (Doty \& Oguri, 1956), has been invoked to explain the pattern of plankton distributions and primary productivity around the Hawaiian Islands (Doty \& Oguri, 1956; Revelante \& Gilmartin, 1973; Gilmartin \& Revelante, 1974) and around a reef in the Great Barrier Reef lagoon in Australia (Hamner \& Hauri, 1981). In each case the phenomenon applied to an oligotrophic environment,

Recently Simpson et al. (1982) presented a model of island mixing based on a cylindrically shaped island oscillating in a stratified sea. The model described the areas of tidally driven vertical mixing observed on the sides of the Scilly Isles in the eutrophic Celtic Sea. They suggested that intrusive flows of this mixed water along the pyconocline, and its accompanying load of inorganic nutrients, were responsible for sustaining the observed subsurface chlorophyll maxima. A similar phenomenon was predicted earlier by Pingree \& Maddock (1979). They developed a hydrodynamical numerical model which derived the tidal characteristics around an island with a regularly sloping bottom topography. Their model also predicted areas of low vertical stability on the sides

* Bigelow Laboratory Contribution No. 82007

(c) Biologische Anstalt Helgoland, Hamburg 
of the island, but in areas of high velocity tidal streaming and depressed sea surface. Pingree \& Maddock (1979) suggested that the high velocity regions could result in centrifugal upwelling (Garrett \& Loucks, 1976), which may be important to phytoplankton growth. We report here historical data on an island system in the coastal Gulf of Maine which support the biological implications of these models.

The coastal Gulf of Maine is most notably characterized by its high biological productivity - driven by the dynamic interactions of large tides, seasonal meteorological changes and water mass formations, relatively large freshwater additions, and an extremely complex bottom topography. These features and processes interact in varying proportions to produce complex upwelling and frontal systems throughout the area (Brown \& Beardsley, 1978; Garrett et al., 1978; Vermersch et al., 1979; Yentsch \& Garfield, 1981). Monhegan Island is situated in just such an environment, approximately $11 \mathrm{~km}$ off the coast of Maine (Fig. 1) on the coastal shelf break, at 80-100 m, with fresher, shallower and more tidally stirred waters shoreward than seaward. The island is also uniquely located within the westward flowing coastal current which is part of the counterclockwise gyre of the Gulf of Maine basin (Bigelow, 1927). These features apparently act together in determining the abundance and distribution of phytoplankton chlorophyll in the waters surrounding Monhegan.

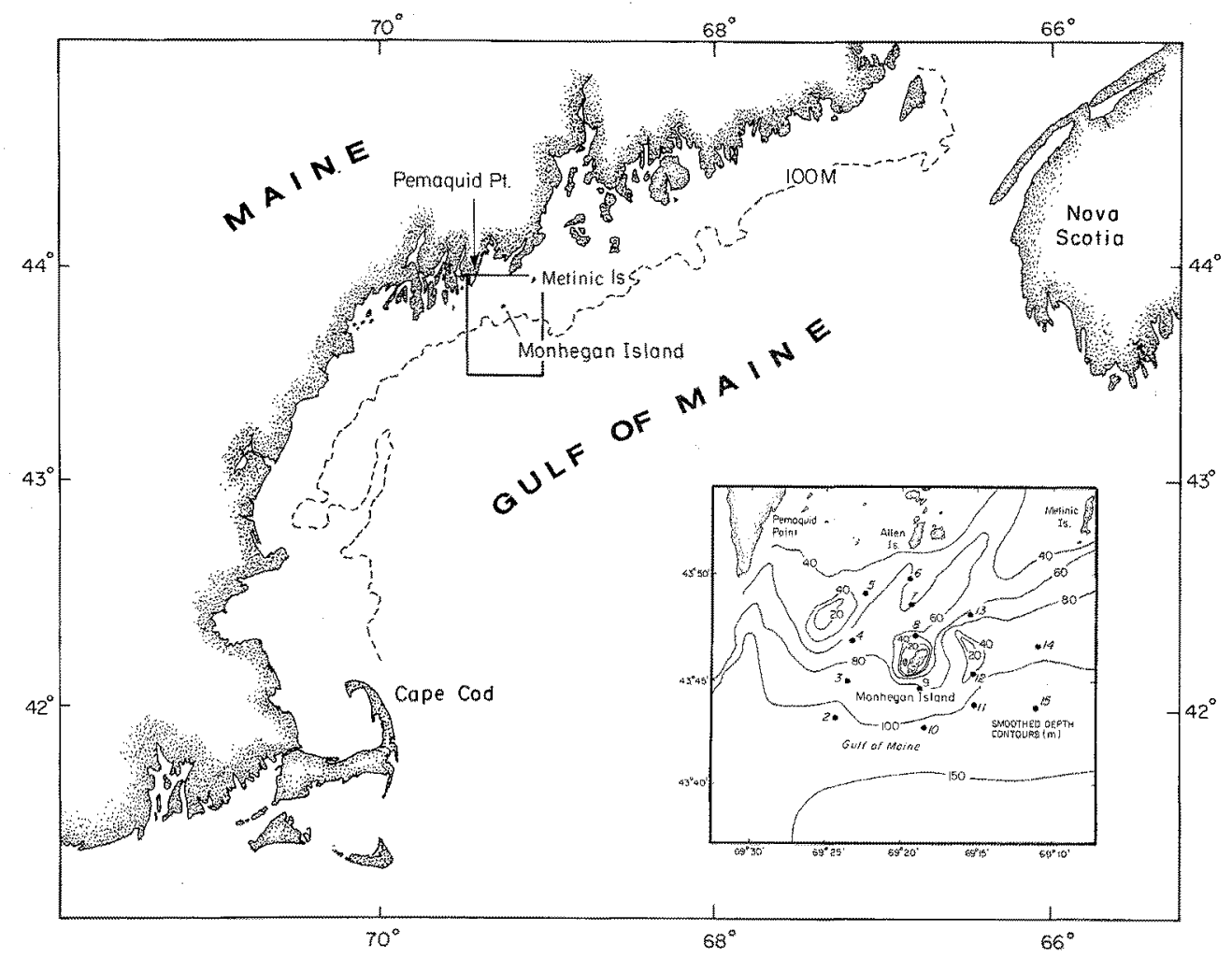

Fig. 1. Map showing the location. of Monhegan Island in the Gulf of Maine. The insert shows the smoothed bottom depth contours and station locations 
Table 1. Maximum tidal speeds $\left(\mathrm{cm} \cdot \mathrm{s}^{-1}\right)$ at four locations around Mohegan Island

\begin{tabular}{|ccccc|}
\hline Depth $(\mathrm{m})$ & \multicolumn{3}{c|}{ Location } & West \\
& North & South & East & 22 \\
5 & 20 & 30 & 20 & 15 \\
\hline
\end{tabular}

\section{METHODS}

Fourteen hydrographic stations around Monhegan Island (Fig. 1) were sampled periodically over a period of five years. Most cruises were conducted during the warmer months, between April and October, and usually consisted of temperature and salinity profile measurements with either an STD or a Beckmann field salinometer, and the collection of water samples from various depths with Niskin bottles for the determination of nutrient and chlorophyll concentrations. The nutrient analyses, usually for nitrate, were performed by the method of Strickland \& Parsons (1972) on water samples which had been frozen at sea. Phytoplankton chlorophyll $\alpha$ was determined by the method of Yentsch \& Menzel (1963).

A series of Lagrangian current measurements were made in the vicinity of Monhegan during July and August, 1979, using cross-vane drogues at $5 \mathrm{~m}$ depth and parachute drogues at $25 \mathrm{~m}$. The two depths were chosen to represent current systems above and below the thermocline which occurs at about $15 \mathrm{~m}$. Each drogue consisted of a styrofoam float with a $3 \mathrm{~m}$ aluminum rod passing through its center and an orange flag and radar reflector attached to each rod. The cross-vane drogues were constructed of two intersecting $32 \times 32 \times 1 \mathrm{~cm}$ sheets of plywood and the parachute drogues had two $61 \mathrm{~cm}$ fabric
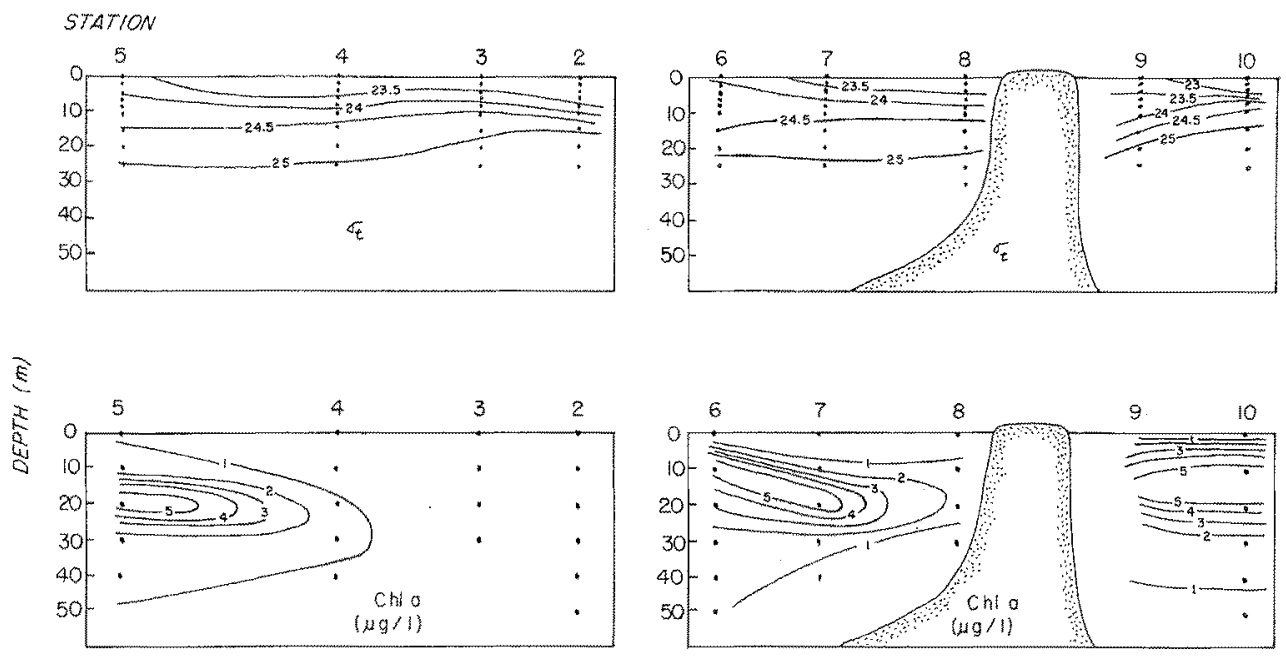

Fig. 2. Vertical sections of density (sigma-t) and chlorophyll $\alpha$ concentrations along two transects on 18 July, 1978 

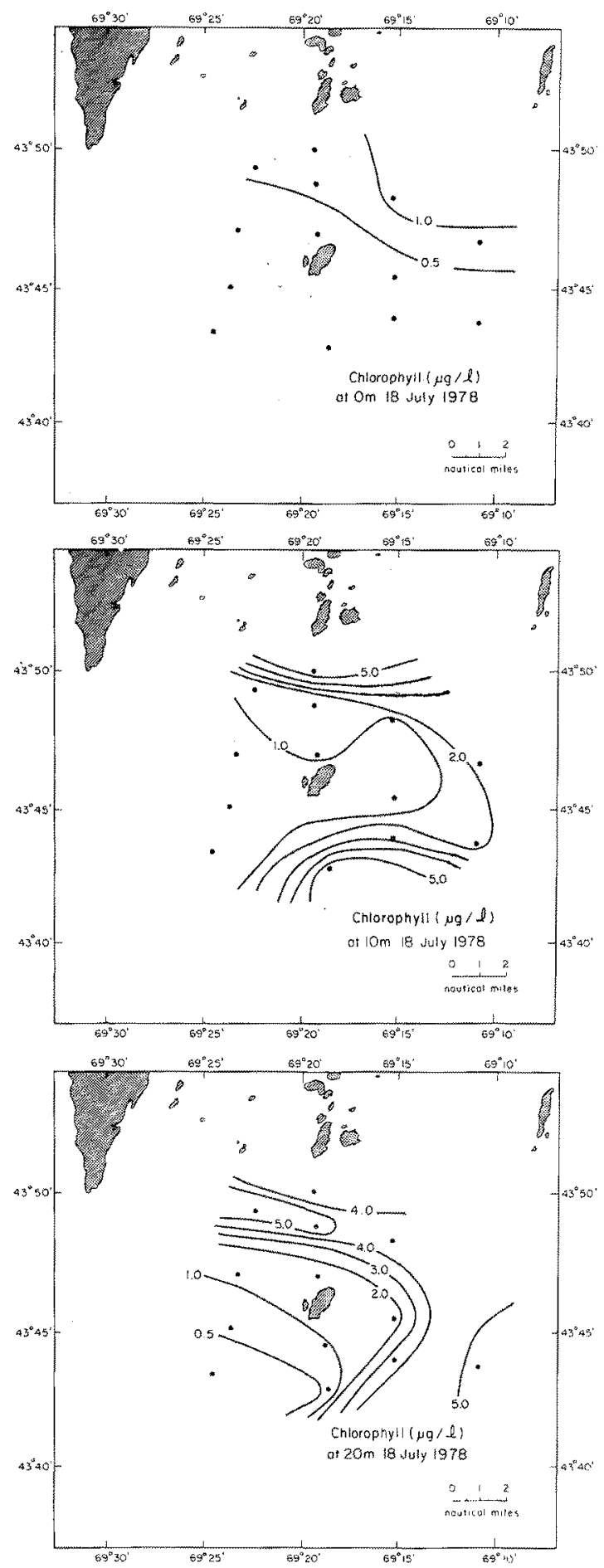

Fig. 3. The horizontal distribution of chlorophyll $\alpha$ around Monhegan at 0,10 and $20 \mathrm{~m}$ for the sample period $18 \mathrm{July,} 1978$ 
parachutes suspended one above the other. Each drogue was attached to its float by a cable and was deployed with an $18 \mathrm{~kg}$ weight attached. The current measurements were conducted in four different locations around the island on four different days, and were tracked by radar for about one tidal cycle.

Sea surface temperatures were measured from airplane overflights using a Barnes PRT-5 Infrared Radiometer equipped with a strip chart recorder. The airplane flew at approximately $70 \mathrm{kts}$ and $150 \mathrm{~m}$ elevation in a radial pattern with Monhegan as the focal point.

\section{RESULTS}

Vertical sections of density (sigma-t) and chlorophyll along two transects about Mohegan Island for the sampling period 18 July, 1978, are shown in Figure 2. These profiles show that there is generally decreased vertical structure shoreward of the island (Stations 5 and 6), most likely the result of wind and tidal mixing at the shallower depths, while stratification seems to be better developed seaward of the island. Somewhat: greater vertical mixing is also apparent at Station 9, just to the south of the island. The patterns of subsurface chlorophyll distributions around Monhegan are presented in profile in Figure 2 and in plan view in Figure 3. These show subsurface chlorophyll maximum layers occurring on the north and south sides of the island at depths of $10-20 \mathrm{~m}$.

Figure 4 shows vertical sections of density, nitrate and chlorophyll for 7 August, 1978. Again, there is evidence of subsurface chlorophyll maxima associated with each
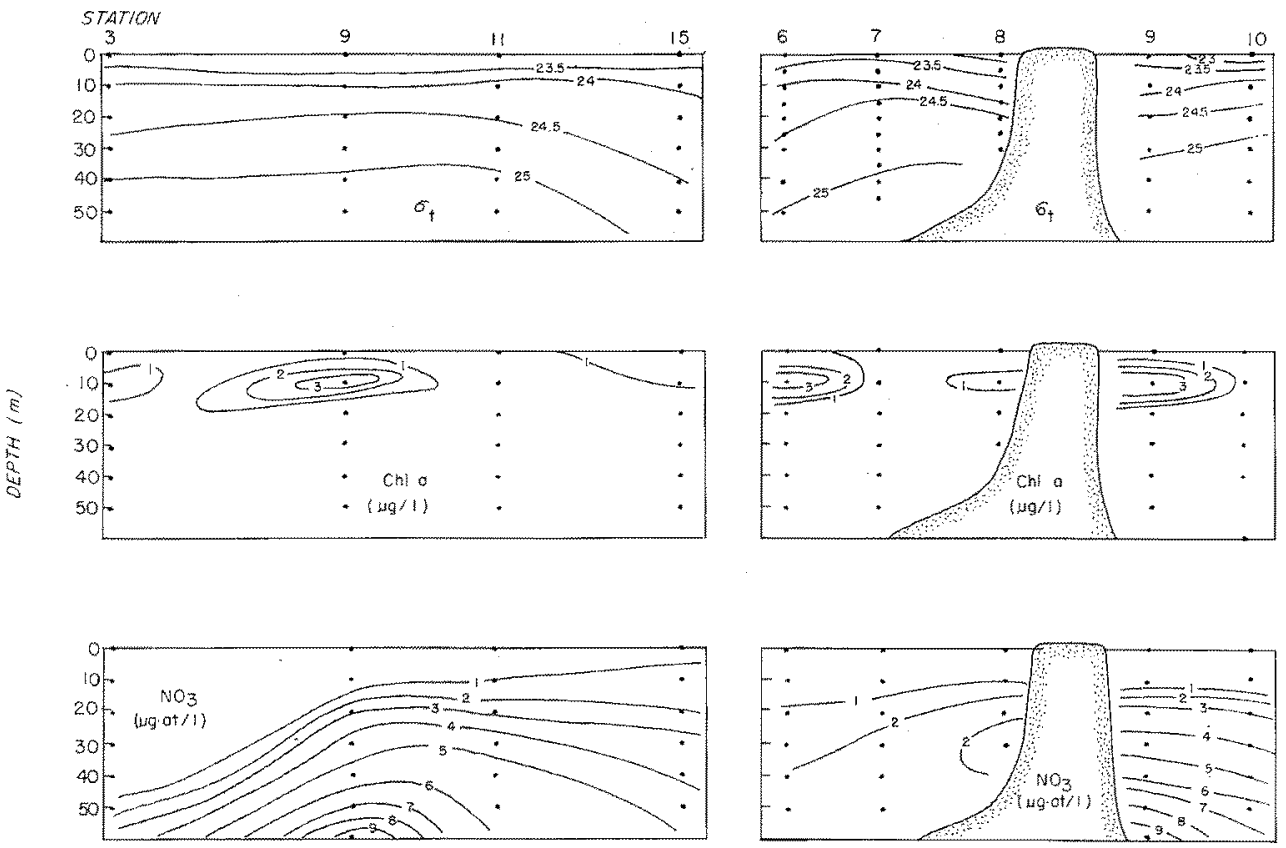

Fig. 4. Vertical sections of density, nitrate and chlorophyll $\alpha$ concentrations along two transects on 7 August, 1978 

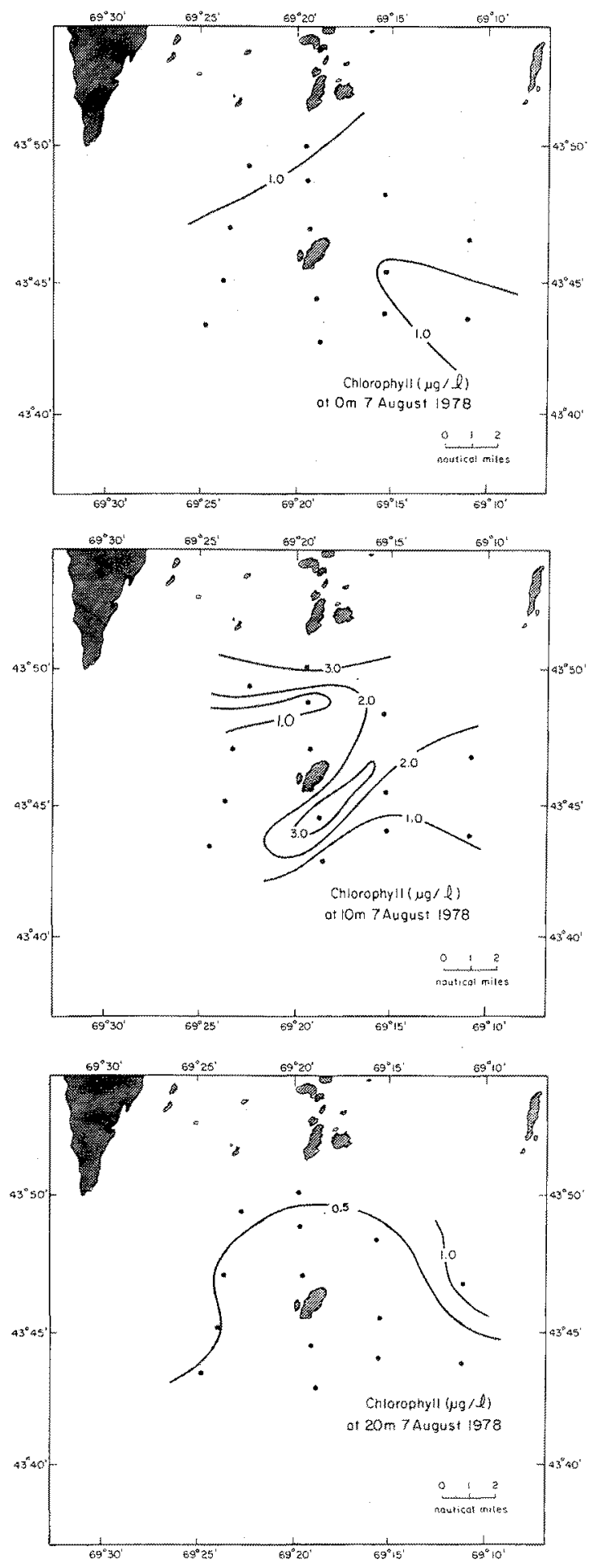

Fig. 5. Same as Figure 3 but for 7 August, 1978 

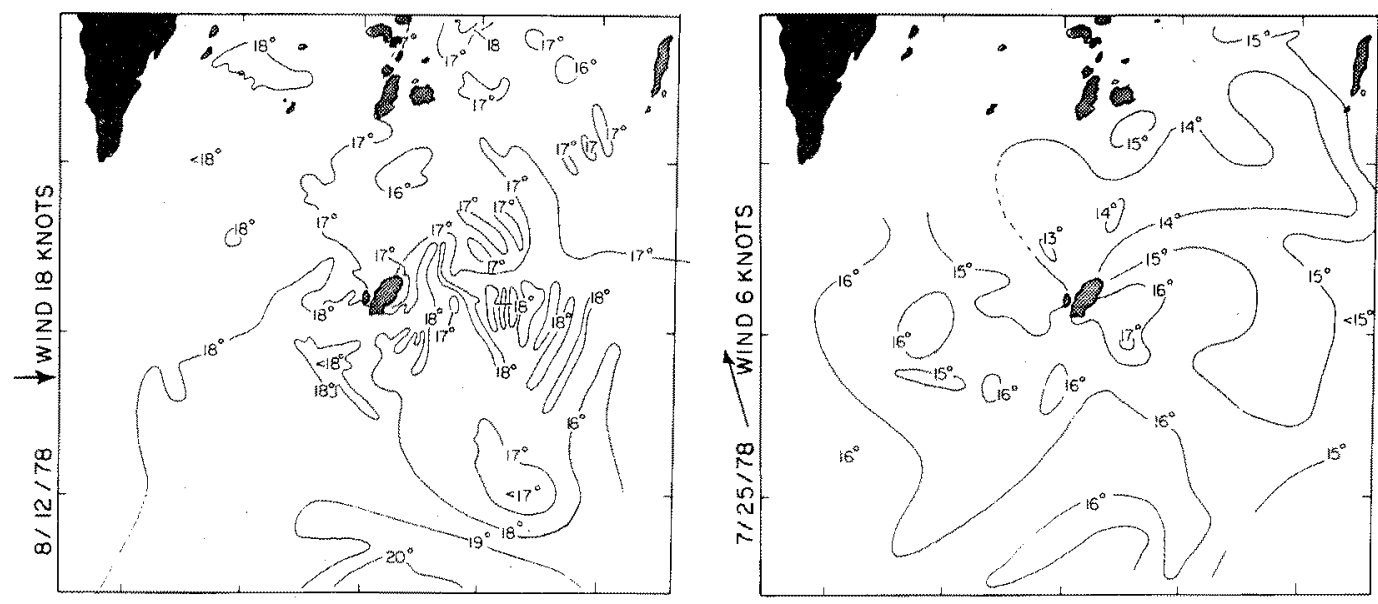

Fig. 6. Maps of remotely sensed (IR) sea surface temperatures $\left({ }^{\circ} \mathrm{C}\right)$ for two airplane overflights, The direction and speed of the wind are indicated for each

side of the island (Figs 4 and 5), which correspond to vertical mixing and possibly upwelling in the areas immediately to the south of the island, and north of the island but closer to the Maine coast.

The results of the airplane remote sensing of sea surface temperatures for two dates are shown in Figure 6. These high resolution temperature maps show that, in general, the surface waters were warmer south of the island, or away from the shallow coastal waters, and cooler inshore. This would indicate that the effects of wind and tidal stirring are felt more so in the shallower nearshore waters, or that there is an upwelling of deeper waters along the coast. The direct influence of wind was difficult to isolate except for the sample on 12 August, 1978, when a strong westerly wind could be seen to promote turbulence in the lee of the island. The position of Monhegan seems to occupy a transition zone with respect to the relative importance of vertical mixing versus stratification. This is indicated by the island's location along thermal fronts oriented along isobaths approximately parallel to the Maine coast (Fig. 1).

The results of the Lagrangian current measurements are presented in Figure 7 . The current drogues north of Monhegan followed an elliptical pattern with a reversal of flow in the east-west direction on successive tidal phases. These elliptical patterns indicate that the water motions in this area are driven primarily by tides and are topographically controlled. All the other drogues followed an average east to west flow component with no reversal on the tide. The apparent flow reversal for the $5 \mathrm{~m}$ drogue deployed south of Monhegan is believed to be the result of its moving into an eddy west of the island. The net non-tidal current speeds and directions determined for each of the four locations around the island are given in Figure $7 \mathrm{~b}$. The maximum tidal speeds observed for each location are given in Table 1 . The quadrants north and south of the island had the greatest differences in net current directions between the $5 \mathrm{~m}$ and $25 \mathrm{~m}$ depths. It is apparent that the $25 \mathrm{~m}$ currents countinue to diverge as they pass the island and the $5 \mathrm{~m}$ currents indicate a convergence on the western side of Monhegan (Fig. 7b). 


\section{DISCUSSION}

The interactions of tides and batymetry around Monhegan Island combined with the island's location within the coastal components of the Gulf of Maine counterclockwise current gyre appear to affect markedly the biological processes of this region. The
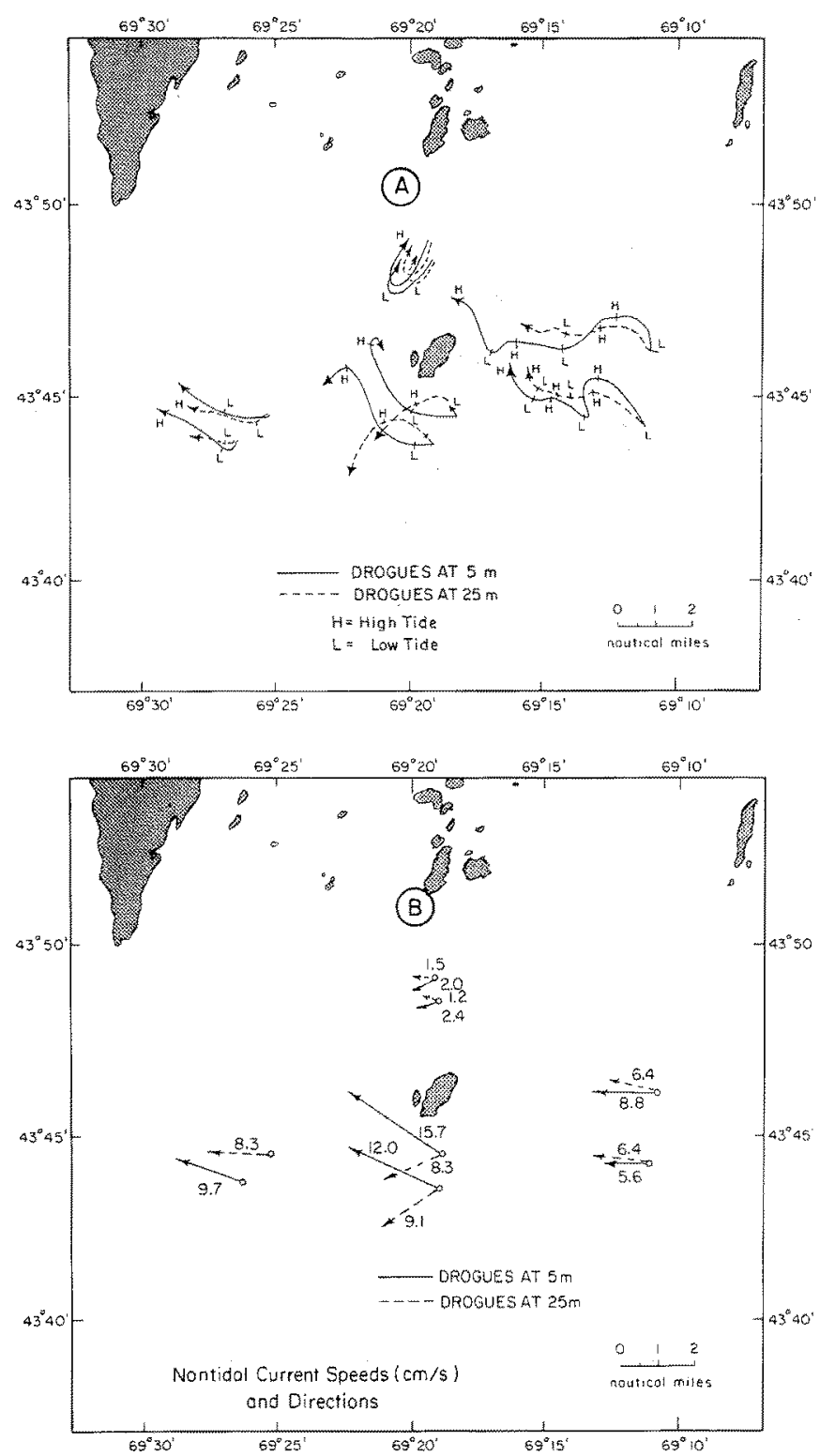

Fig. 7. Results of current drogue experiments during July and August, 1979. Panel A shows the drogue paths for the durations indicated by the tidal stages. Panel B shows the net nontidal current speeds and directions. The maximum tidal speeds are given in Table 1 
shallower waters north of Monhegan near Allen Island and the Maine coast are probably more susceptible to tidally induced vertical mixing than the deeper waters seaward. Yentsch \& Garfield (1981), using satellite imagery, showed that vertical mixing in the Georges Bank - Gulf of Maine area extended to as deep as $60 \mathrm{~m}$. They pointed out that this destratification depth was deeper than that predicted from the model by Garrett et al. (1978) $(30-40 \mathrm{~m})$, which considered tidal mixing only, and that processes other than tides are important in destratifying the water column. A destratification depth of $60 \mathrm{~m}$ would include the waters inshore of Monhegan although our results showed that rather than complete destratification, those waters were merely less vertically stratified than deeper water south of the island. Less vertical structure inshore is also demonstrated by the patterns of remotely sensed surface temperatures which showed the correlation between bathymetry and thermal fronts, with a more vertically mixed water column having cooler surface temperatures inshore. We suspect that since vertical mixing inshore is not complete, upwelling along the Maine coast may be important in maintaining the higher chlorophyll levels seen there. Graham (1970) concluded that upwelling is the most prominent feature of the coastal Maine circulation.

It is quite possible that more complete destratification could occur during periods of vertical mixing by major spring tides, especially when one considers the extremely irregular bottom topography in this area and the associated bottom friction that would ensue. Balch (1981) showed that higher phytoplankton abundances occurred in the waters surrounding Monhegan Island during and after (0-5 days) major spring tides. His results would indicate that vertical mixing and nutrient replenishment does occur at such times.

The relatively high concentrations of chlorophyll to the south of Monhegan seem to be related to a variety of processes. There is vertical mixing immediately adjacent to the island, as indicated by the more widely spaced isopycnals at Station 9 , and possibly upwelling, as indicated by the high concentrations of nitrate (Fig. 4). The high velocity region to the south of the island may provide the energy not only to mix the water column, but it apparently forces the upwelling there (Pingree \& Maddock, 1979) similar to the centrifugal upwelling described by Garrett \& Loucks (1976). In addition, the shoal area to the east of Monhegan (Fig. 1) may exert a residual circulation (e.g. Robinson, 1981) that reinforces these processes. The intermediate density water mixture which results could then be advected radially away from the flank of the island, carrying with it sufficient nutrients to support the subsurface chlorophyll maximum which is in keeping with the model of Simpson et al. (1981).

In summary, although our historical data were not complete enough to allow rigorous modelling, an island mixing effect which we observed around Monhegan Island in the Gulf of Maine appears to support the models of Pingree \& Maddock (1979) and Simpson et al. (1982) to produce higher standing stocks of phytoplankton in an already productive region. Further observations may show that this is a universal feature of island systems in shallow continental shelf seas where tides dominate the water motions.

Acknowledgements. We thank the following for valuable assistance in the field and in the laboratory: N. Garfield, T. Fopkins, D. Phinney, J. Laird, C. Garside, C. S. Yentsch, P. M. Holligan, F. Mague, J. Litinowich, A. Mersfelder, and the people of Monhegan Island. We thank Peg Colby and Pat Oathout for the typing, and Jim Rollins for drafting the figures. This research was funded in part by FDA, NIEF, and the State of Maine. 


\section{LITERATURE CITED}

Balch, W. M., 1981. An apparent lunar tidal cycle of phytoplankton blooming and community succession in the Gulf of Maine. - J. exp. mar. Biol. Ecol. 55, 65-77.

Bigelow, H. B., 1927. Physical oceanography of the Gulf of Maine. - Bull. Bur. Fish., Wash. 40, 511-1027.

Brown, W. S. \& Beardsley, R. C., 1978. Winter cooling in the western Gulf of Maine: Part 1. Cooling and water mass formation. - J. phys. Oceanogr. 8, 265-277.

Doty, M. S. \& Oguri, M., 1956. The island mass effect. - J. Cons. perm. int. Explor. Mer. 22, 33-37.

Garrett, C. J. R. \& Loucks, R. H., 1976. Upwelling along the Yarmouth shore of Nova Scotia. -J. Fish. Res. Bd Can. 33, 116-117.

Garrett, C. J. R., Keeley, J. R. \& Greenberg, D. A., 1978. Tidal mixing versus stratification in the Bay of Fundy and Gulf of Maine. - Atmosphere-Ocean 16, 403-423.

Gilmartin, M. \& Revelante, N., 1974. The "island mass effect" on the phytoplankton and primary production of the Hawaiian Islands. - J, exp. mar. Biol. Ecol. 16, 181-204.

Graham, J. J., 1970. Coastal currents of the western Gulf of Maine. - Res. Bull. int. Commn N. W. atl. Fish., 7, 1-32.

Hamner, W. M. \& Hauri, I. R., 1981. Effects of island mass: Water flow and plankton pattern around a reef in the Great Barrier Reef lagoon, Australia. - Limnol. Oceanogr. 26, 1084-1102.

Pingree, R. D. \& Maddock, L, 1979. Tidal flow around an island with a regularly sloping bottom topography. - J. mar. biol. Ass. U. K. 59, 699-710.

Revelante, N. \& Gilmartin, M., 1973. Some observations on the chlorophyll maximum and primary production in the eastern North Pacific. - Int. Rev. ges. Hydrobiol. 58, 819-833.

Robinson, I. S., 1981. Tidal vorticity and residual circulation. - Deep-Sea Res. 28A, 195-212.

Simpson, J. H., Tett, P. B., Argote-Espinoza, M. L., Edwards, A., Jones, K. L. \& Savidge, G., 1982. Mixing and phytoplankton growth around an island in a stratified sea. - Cont. Shelf Res. 1 , 15-31.

Strickland, J. D. \& Parsons, T. R., 1972. A practical-handbook of seawater analysis. - Bull. Fish. Res. Bd Can. 167, 1-310.

Vermersch, J. A., Beardsley, R. C. \& Brown, W. S., 1979. Winter circulation in the western Gulf of Maine: Part 2. Current and pressure observations. - J. phys. Oceanogr. 9, 768-784.

Yentsch, C. S. \& Garfield, N., 1981. Principal areas of vertical mixing in the waters of the Gulf of Maine, with reference to the total productivity of the area. In: Oceanography from space. Ed. by J. F. R. Gower. Plenum Press, New York, 303-312.

Yentsch, C. S. \& Menzel, D. W., 1963. A method for the determination of phytoplankton chlorophyll and phaeophytin by fluorescence. - Deep-Sea Res. 10, 443-448. 